\title{
Do Higher Resource Capture Ability and Utilization Efficiency Facilitate the Successful Invasion of Exotic Plant? A Case Study of Alternanthera philoxeroides
}

\author{
Xuyan Geng, Shang Jiang, Bo Li, Xiaoyun Pan* \\ Coastal Ecosystems Research Station of Yangtze River Estuary, Ministry of Education Key Laboratory for Biodiversity Science \& \\ Ecological Engineering, Institute of Biodiversity Science, Shanghai, China. \\ Email: xypan@fudan.edu.cn
}

Received June $16^{\text {th }}, 2013$; revised July $20^{\text {th }}, 2013$; August $20^{\text {th }}, 2013$

Copyright (C) 2013 Xuyan Geng et al. This is an open access article distributed under the Creative Commons Attribution License, which permits unrestricted use, distribution, and reproduction in any medium, provided the original work is properly cited.

\begin{abstract}
We tested the hypothesis that introduced populations may have higher resource capture ability and utilization efficiency than native ones of invasive plants. We compared ecophysiological traits including maximum photosynthetic rate $\left(\mathrm{P}_{\max }\right)$, apparent quantum yield (Q), specific leaf area (SLA), photosynthetic energy use efficiency (PEUE), photosynthetic nitrogen use efficiency (PNUE), water use efficiency (WUE), mass-based and area-based leaf construction cost $\left(\mathrm{CC}_{\text {mass }}\right.$ and $\mathrm{CC}_{\text {area }}$ ), and mass-based and area-based leaf nitrogen concentration $\left(\mathrm{N}_{\text {mass }}\right.$ and $\mathrm{N}_{\text {area }}$ ) between native (Argentina) and introduced (USA) populations of two varieties (North Apa and South Apo) of Alternanthera philoxeroides under common garden conditions in China. For Apo and Apa, $\mathrm{P}_{\max }, \mathrm{Q}, \mathrm{N}_{\text {mass }}$ and WUE were not significantly different between native and introduced populations; introduced populations had significantly lower SLA and lower $\mathrm{CC}_{\text {mass }}$ but significantly higher $\mathrm{N}_{\text {area }}$ and $\mathrm{CC}_{\text {area }}$ than native ones. For Apa, the introduced populations showed significantly lower PEUE and lower PNUE while for Apo, PEUE and PNUE were not significantly different between native and introduced populations. The results indicated that introduced populations of $A$. philoxeroides do not show higher resource capture ability and resource utilization efficiency than their native ones in the common garden experiment, suggesting that these traits may not necessarily contribute to successful invasion of invasive plants.
\end{abstract}

Keywords: Invasive Plant; Resource Use Efficiency; Construction Cost; Leaf Nitrogen

\section{Introduction}

One mechanism which has been frequently mentioned and investigated empirically in the context of plant invasions is that higher resource capture ability and utilization efficiency may facilitate successful invasion [1-3]. Studies comparing leaf traits of invasive plants and native plants have shown that invasive species have higher specific leaf area (SLA) [4,5], lower mass-based leaf construction cost $\left(\mathrm{CC}_{\text {mass }}\right)$ [4,6-8], higher photosynthetic nitrogen use efficiency (PNUE) [3,4,9], higher photosynthetic energy use efficiency (PEUE) $[8,10]$ and higher water use efficiency (WUE) $[9,11]$ than native species. However, some studies have detected that there are no significant differences in $\mathrm{CC}_{\text {mass }}$ [12], PNUE [8] and WUE $[6,8]$ between invaders and natives. A recent study

"Corresponding author. also suggests that the populations in the introduced range of an invasive species have evolved a higher PEUE and a shorter payback time but not lower $\mathrm{CC}_{\text {mass }}$ than those in the native range [13].

Do exotic invasive plants have generally evolved higher resource capture ability and utilization efficiency in their introduced ranges? To answer this question, we compared leaf-level physiological traits that are related to resource capture and utilization efficiency, e.g., maximum photosynthetic rate $\left(\mathrm{P}_{\max }\right)$, apparent quantum yield, SLA, PNUE, PEUE, WUE, area-based leaf construction cost $\left(\mathrm{CC}_{\text {area }}\right)$ and $\mathrm{CC}_{\text {mass }}$, area-based leaf nitrogen contention $\left(\mathrm{N}_{\text {area }}\right)$ and mass-based nitrogen contention $\left(\mathrm{N}_{\text {mass }}\right)$, between native (Argentina) and introduced (USA) populations of two varieties of Alternanthera philoxeroides (alligator weed) under common garden conditions in Shanghai, China. 


\section{Materials and Methods}

\subsection{Plant Species}

Alternanthera philoxeroides (alligator weed), a clonal herbaceous perennial native to South America, is distributed from Buenos Aires province to southern Brazil $\left(18^{\circ} \mathrm{S}-39^{\circ} \mathrm{S}\right)[14]$. It has been widely introduced to warm temperate and subtropical humid areas in North America, Australia and China [15]. At present, A. philoxeroides is one of the most noxious weeds in wetlands and agro ecosystems [16]. Many attributes have contributed to the invasion success of $A$. philoxeroides in China, such as rapid vegetative growth and reproduction [15], higher phenotypic plasticity than its native congener $A$. sessilis $[16$, 17] and adaptation to physical disturbances[18].

A. philoxeroides typically emerges from belowground buds (on storage roots) in spring and then spreads vegetatively throughout a growing season, consequently forming dense monospecific stands. It overwinters with storage roots and rhizomes [18]. Although A. philoxeroides may produce viable seeds, sexual reproduction contributes little to population regeneration due to extremely low seed outputs and low germination rates $[14,15]$. In contrast, vegetative propagation (with storage roots and stems) is its primary regeneration strategy in the field [14].

At least two varieties of $A$. philoxeroides are recognized in Argentina [19]: the northern A. p. var. acutifolia (Apa) and the southern A. p. var. obtusifolia (Apo) [20]. The two varieties are distributed in different geographic areas and habitat types (Figure 1(a); Flooding Pampa grasslands vs. wetlands along the Middle Parana River), and have evolved different leaf and stem morphologies $[19,20]$. Both Apa and Apo have been introduced into USA (Figure 1(b)) [21].

In 2003 and 2004 we sampled stem fragments of $A$. philoxeroides from 16 populations: eight Argentina populations and eight USA populations (Figure 1). Both Argentina and USA populations were sampled widely across their distribution range. We collected $10-20$ stems for each population (more than $20 \mathrm{~m}$ apart from each other to ensure that different clones/genets might be sampled). All collected stems were cloned in a greenhouse for more than 3 years to reduce environmental maternal effects.

\subsection{Experiment Design}

The study was carried in August 2012 at the Experimental Field Unit of Fudan University, Shanghai, China, which is an outdoor field previously used for other garden experiments. The climate is humid subtropical, with rainfall averaging $1160 \mathrm{~mm}$ per year and with mean monthly temperatures ranging from $27.9^{\circ} \mathrm{C}$ in July to

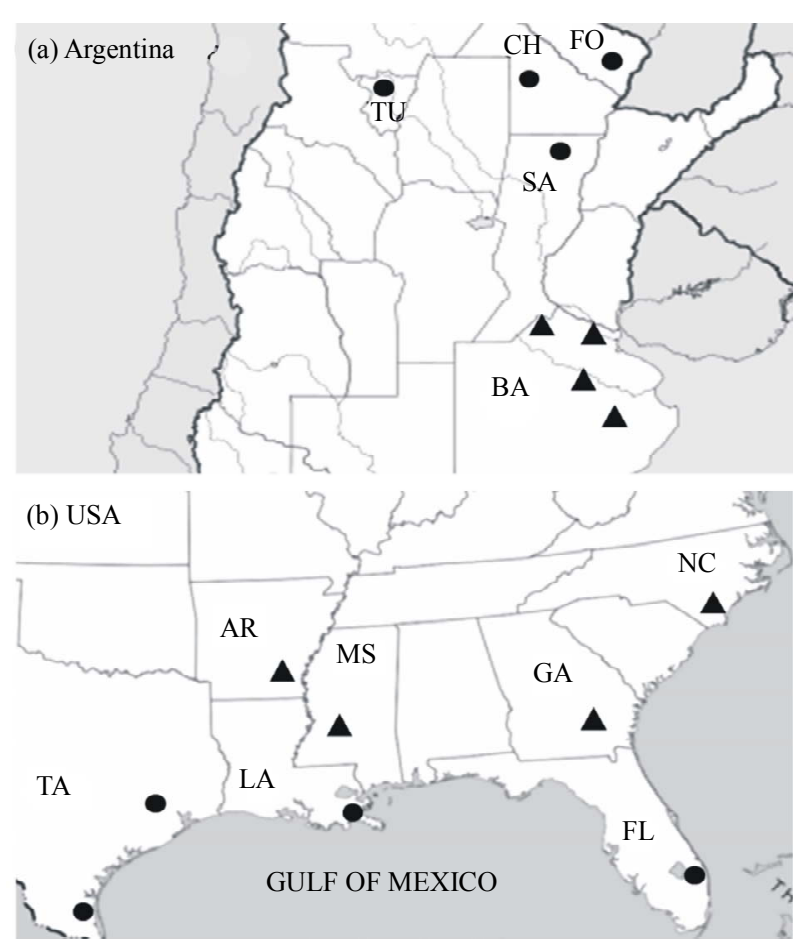

Figure 1. Sample sites of two varieties, Apa (black circle) and Apo (black triangle), of Alternanthera philoxeroides from native (Argentina) and introduced (USA) range.

$4.2^{\circ} \mathrm{C}$ in January. In July 2011, we vegetative cloned 16 populations in experiment garden. Two weeks later we selected four individuals (with $2-3$ internodes and four or six leaves) per populations, and planted them individually at a depth of $2 \mathrm{~cm}$ in round pots (diameter, $23 \mathrm{~cm}$; depth, $18 \mathrm{~cm}$ ).We used nutrient soil (Beilei, Beilei Organic Fertilizer Co., Ltd., Zhenjiang, China) with the content of $\mathrm{N}, \mathrm{P}, \mathrm{K} \geq 2 \%$ (dry weight basis), organic matter $\geq 35 \%$ (dry weight basis), water $\leq 45 \%$, and $\mathrm{pH} 5.5-6.5$. All pots were randomly arranged on a desk and re-randomized weekly to reduce position effects. Pots were watered by hand every other day to keep the substrate moist.

We harvested all plant materials 8 weeks after planting. Each plant was separated into leaves, stems, and roots. We determined leaf area for each plant with a leaf area meter (LI-3100A; LI-COR, Lincoln, NB, USA). All materials were oven dried at $55^{\circ} \mathrm{C}$ for $72 \mathrm{~h}$ and then weighed to the nearest $0.001 \mathrm{~g}$. SLA $\left(\mathrm{cm}^{2} \cdot \mathrm{g}^{-1}\right)$ was calculated as the ratio of leaf area to leaf dry mass. And then we finely ground the dried leaves.

Mass-based carbon concentration (C) and $\mathrm{N}_{\text {mass }}$ of the powdered leaves were determined with OEA analyzer (Organic Elemental Analysis, FlashEA1112, Thermo Finnigan, Italy). Ash concentration (Ash) was determined after combusting leaf sample in a muffle furnace at $550^{\circ} \mathrm{C}$ for $6 \mathrm{~h}$. Ash alkalinity (AA) was determined acidimetrically [22]. The mineral concentration (Min) of 
each sample was calculated according to [22] as follows:

$$
\mathrm{Min}=\mathrm{Ash}-\mathrm{AA} \times 30+\text { Nitrate, }
$$

$\mathrm{CC}_{\text {mass }}$ can be calculated $[23,24]$ as follows:

$$
\begin{aligned}
\mathrm{CC}= & {\left[-1.041+5.077 \times \frac{\mathrm{C}}{1000-\mathrm{Min}}\right] } \\
& \times \frac{1000-\mathrm{Min}}{1000}+\left(5.325 \times \frac{\mathrm{Norg}}{1000}\right) .
\end{aligned}
$$

Nitrate concentration were negligible, thus we assumed that $\mathrm{N}_{\text {org }}=\mathrm{N}_{\text {mass }}[25]$.

\subsection{Determination of Physiological Traits}

Net photosynthetic rate in relation to varying photosynthetic photon flux density (light response curves) was determined on the youngest fully-expanded leaves with a Li-6400 Portable Photosynthesis System (LI-6400; LICOR, Lincoln, NB, USA). Measurements were made on 2 - 3 representative leaves on 4 individuals of each varieties in a pair during continuously sunny days from 09:00 to 12:00 am in the field in August 2012. All leaves of the Argentina and USA populations in a pair were of similar age and position on the stems. PPFD decreased in a stepwise fashion from 2000 to $0 \mu \mathrm{mol}$ photon $\mathrm{m}^{-2} \cdot \mathrm{s}^{-1}$ (at 2000, 1500, 1200, 1000, 800, 600, 400, 200, 150, 100, 70, 50 , and 0 ). During the measurements, $\mathrm{CO}_{2}$ concentration, temperature and relative humidity within the leaf chamber were similar to those of ambient conditions. Each leaf was acclimated for 10 - $20 \mathrm{~min}$ to $2000 \mu \mathrm{mol}$ photon $\mathrm{m}^{-2} \cdot \mathrm{s}^{-1}$ of PPFD prior to the measurement.

We fitted entire light response curves using the nonrectangular hyperbola model according to [26] as shown in Equation (3), where Photo is the leaf net photosynthesis rate, $P A R$ is the light intensity, $P_{\max }$ is maximum photosynthetic rate, $\mathrm{Q}$ is apparent quantum yield, $\mathrm{R}$ is dark respiration rate and $\mathrm{K}$ is a constant.

$\mathrm{N}_{\text {area }}\left(\mathrm{g} \cdot \mathrm{m}^{-2}\right)=\mathrm{N}_{\text {mass }} / \mathrm{SLA}$;

$\mathrm{CC}_{\text {area }}\left(\mathrm{g} \cdot \mathrm{glucose} \cdot \mathrm{m}^{-2}\right)=\mathrm{CC}_{\text {mass }} / \mathrm{SLA}$;

PEUE $\left(\mu \cdot \mathrm{mol} \mathrm{CO} \mathrm{g}_{2}\right.$ glucose $\left.\mathrm{C}^{-1} \cdot \mathrm{s}^{-1}\right)=\mathrm{P}_{\max } / \mathrm{CC}_{\text {area }}[6]$;

$\operatorname{PNUE}\left(\mu \cdot \mathrm{mol} \mathrm{CO} \mathrm{g}^{-1} \cdot \mathrm{s}^{-1}\right)=\mathrm{P}_{\max } / \mathrm{N}_{\text {area }}[27]$;

$\operatorname{WUE}\left(\mu \cdot \mathrm{molCO}_{2} \mu \mathrm{mol}^{-1} \mathrm{H}_{2} \mathrm{O}\right)=\mathrm{P}_{\max } / \mathrm{E}$ (transpiration) $[9,28]$.

\subsection{Statistical Analysis}

Nested analysis of variance (ANOVA) was used to compare if there had differences between plants from invasive and native populations in parameters $\left(\mathrm{P}_{\max }\right.$, apparent quantum yield, SLA, PNUE, PEUE,WUE, $\mathrm{CC}_{\text {area }}, \mathrm{CC}_{\text {mass }}$,
$\mathrm{N}_{\text {area }}$ and $\mathrm{N}_{\text {mass }}$ ), with range (Argentina vs. USA) as a fixed factor, population nested within range as a random factor. The residuals for all tests were normally distributed and no transformations were necessary. All analyses were carried out using SPSS 13.0 (SPSS, Chicago, USA).

\section{Results}

For both Apo and Apa, $\mathrm{P}_{\max }$ (Figure 2(a)) and apparent quantum yield (Figure 2(b)) were not significantly different between native and introduced populations, and introduced populations had significantly lower SLA (Figure 2(c)).

For Apa the introduced populations showed significantly lower PEUE and PNUE, while for Apo, PEUE and PNUE were not significantly different between native and introduced populations (Figures 3(a) and (b)). For both Apa and Apo, WUE were not significantly different between native and introduced populations (Figure 3(c)).

For both Apa and Apo, $\mathrm{N}_{\text {mass }}$ were not significantly different between native and introduced populations (Figure 4(a)), but introduced populations had significantly higher $\mathrm{N}_{\text {area }}$ than native ones (Figure 4). Introduced populations showed significantly lower $\mathrm{CC}_{\text {mass }}$ (Figure 4(c)), but significantly higher $\mathrm{CC}_{\text {area }}$ (Figure 4(d)) than native ones.

\section{Discussion}

\subsection{Resource Capture Ability}

Our results showed that introduced populations of A. philoxeroides showed no significant difference in $\mathrm{P}_{\max }$, apparent quantum yield, and $\mathrm{N}_{\text {mass }}$ relative to the native populations, suggesting that invasive populations of $A$. philoxeroides do not have advantage in resource capture ability compared to their native populations. This result was inconsistent with previous studies. Previous studies have found that most invasive plants have higher $\mathrm{P}_{\max }$ $[6,9,11]$ compared to their co-occurring natives. Ref [8] found that invasive species had significantly higher $\mathrm{P}_{\max }$ (mass-based) than their non-invasive alien congeners. In a study of comparing the functional traits between plants from invasive and native populations of alien plant, higher $\mathrm{P}_{\max }$ and higher SLA of invasive populations was also found [13].

SLA can be envisaged as an indicator of thickness or density; leaves with a higher SLA are typically thin and have greater levels of herbivory [29]. Our results showed that invasive plants of $A$. philoxeroides had significantly lower SLA than their corresponding natives, indicating

$$
\text { Photo }=\frac{\mathrm{PAR} \times \mathrm{Q}+\mathrm{P}_{\max }-\sqrt{\left(\mathrm{PAR} \times \mathrm{Q}+\mathrm{P}_{\max }\right)^{2}-4 \times \mathrm{PAR} \times \mathrm{Q} \times \mathrm{P}_{\max } \times \mathrm{K}}}{2 \mathrm{~K}}-\mathrm{R} \text {. }
$$



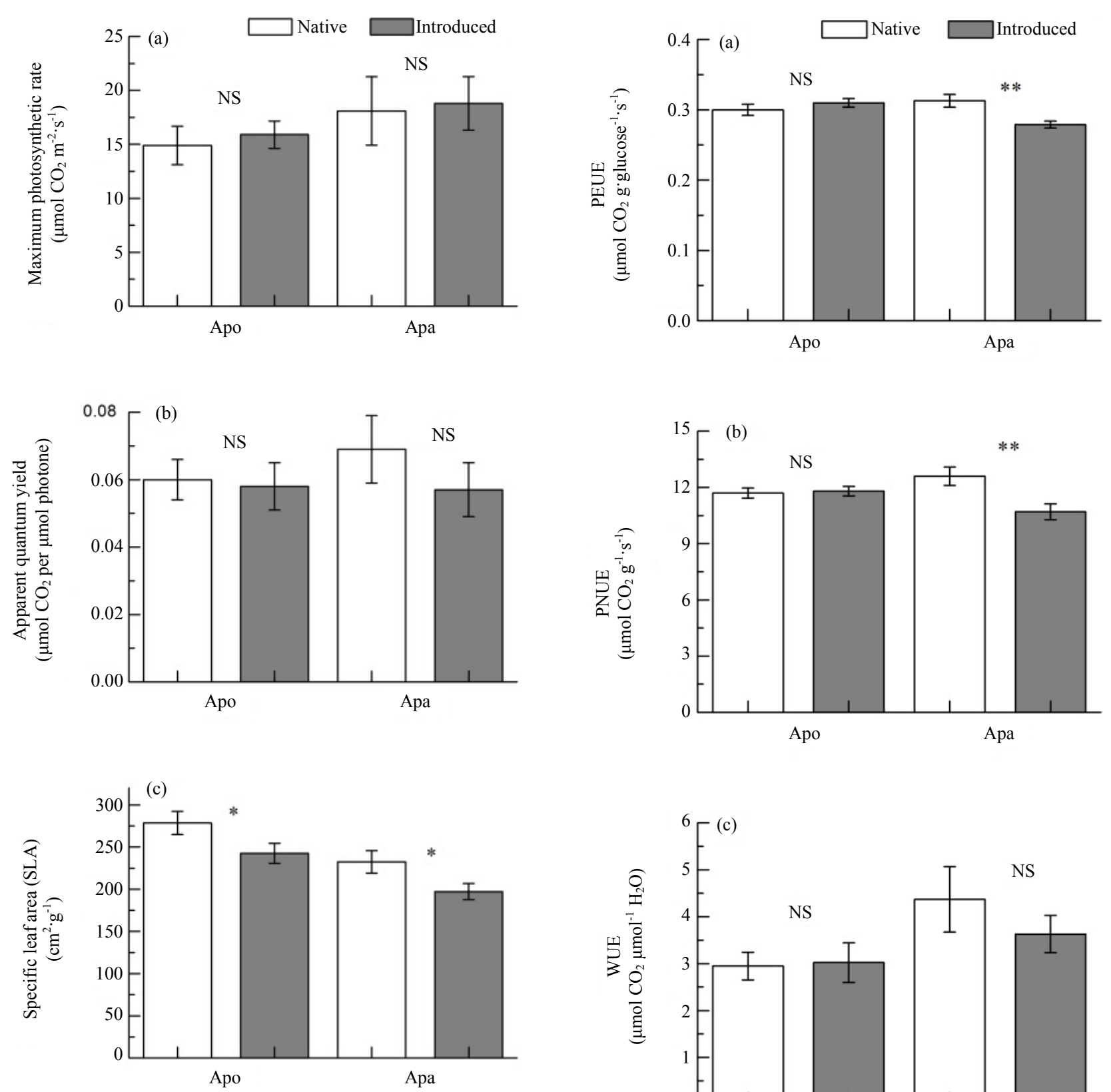

Figure 2. Differences in maximum photosynthetic rate $\left(P_{\max }\right.$ (a), apparent quantum yield (b) and specific leaf area (SLA) (c) between native (Argentina) and introduced (USA) populations of two varieties (Apo and Apa) of Alternanthera philoxeroides. Dates are means \pm SE (NS, no significant differences, $* P<0.05)$.

introduced populations of A. philoxeroides may have evolved higher resistance to generalist herbivores than native ones (Pan et al. unpublished results).

\subsection{Resource Utilization Efficiency}

Our results showed that invasive Apa had significantly lower PEUE and PNUE than native Apa, and invasive

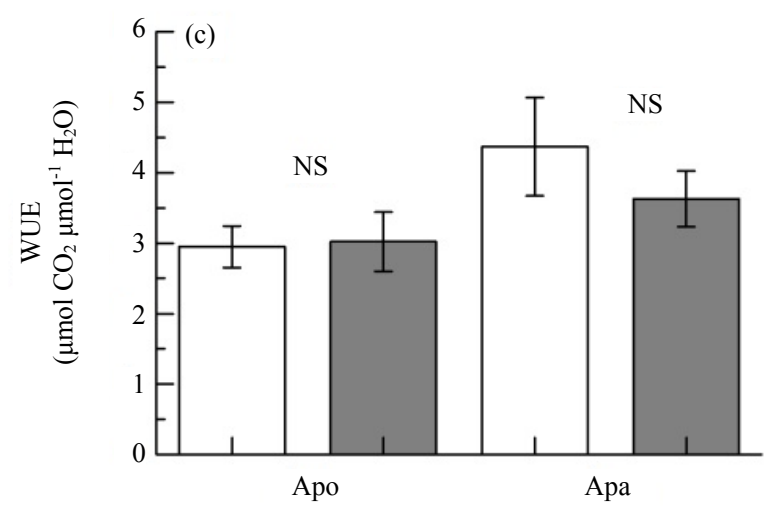

Figure 3. Differences in photosynthetic energy use efficiency (PEUE) (a), photosynthetic nitrogen use efficiency (PNUE) (b) and water use efficiency (WUE) (c) between native (Argentina) and introduced (USA) populations of two varieties (Apo and Apa) of Alternanthera philoxeroides. Dates are means \pm SE (NS, no significant differences, $* P<0.05$ and $* * P<0.01)$.

Apo had no significant difference in PEUE and PNUE compared to native Apo. These results indicate that introduced populations of A. philoxeroides do not have higher resource utilization efficiency than their native ones in the common garden experiment. This contrasts 

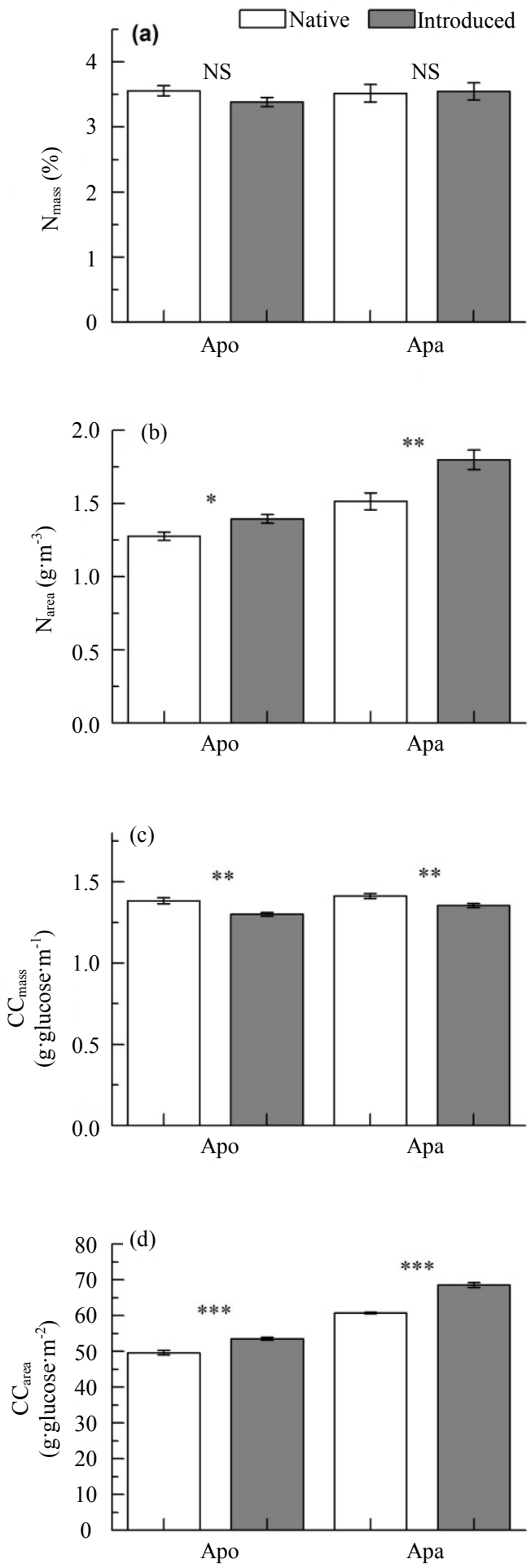

Figure 4. Differences in mass-based nitrogen concentration $\left(N_{\text {mass }}\right)$ (a) area-based nitrogen concentration $\left(N_{\text {area }}\right)$ (b) mass-based construction cost $\left(C C_{\text {mass }}\right)$ (c) and area-based construction cost $\left(C C_{\text {area }}\right)$ (d) between native (Argentina) and introduced (USA) populations of two varieties (Apo and Apa) of Alternanthera philoxeroides. Dates are means \pm SE (NS, no significant differences, $* P<0.05$, $* * P<0.01$ and $* * * P<0.001)$. with previous studies. Invasive plants have often higher PNUE $[4,9,30]$, higher PEUE [8] or both higher PEUE and PNUE $[6,10,12]$ than natives species. Also in their work comparing energy use strategy of an invasive species from populations of its native ranges and introduced ranges, Ref. [13] found that plants from invasive populations had a higher PEUE than native populations.

Our results showed that invasive populations of A. philoxeroides had significantly lower $\mathrm{CC}_{\text {mass }}$ and the same levels of $\mathrm{N}_{\text {mass }}$ compared with native populations. However, due largely to significantly lower SLA, invasive populations had significantly higher $\mathrm{CC}_{\text {area }}$ and $\mathrm{N}_{\text {area }}$ than native populations (Figure 4). Nitrogen allocation to the photosynthetic apparatus is suggested to be a major factor responsible for the interspecific variation in PNUE [31]. Introduced Apa had the same leaf $\mathrm{N}_{\text {mass }}$ but significantly lower PNUE than native ones, suggesting a decreased fraction of leaf nitrogen invested in the photosynthetic apparatus in introduced plants of Apa.

WUE did not differ between native and invasive populations of A. philoxeroides, which is accordant with previous results that invasive plants are not at an advantage over native species in WUE $[6,8,9]$.

Our finding that introduced populations of A. philoxeroides do not have higher resource capture ability and resource utilization efficiency than their native ones in the common garden experiment, suggesting that these traits may not necessarily contribute to successful invasion of invasive plants.

The importance of resource use efficiency will vary across habitats and timescales [6]. Future research will be needed to examine if there are differences in resource capture ability and utilization efficiency between introduced and native populations of invasive plants across resource gradients and across their whole growth seasons.

\section{Acknowledgements}

This study was financially supported by the National Natural Science Foundation of China (31070369).

\section{REFERENCES}

[1] C. C. Daehler, "Performance Comparisons of Co-Occurring Native and Alien Invasive Plants: Implications for Conservation and Restoration," Annual Review of Ecology, Evolution, and Systematics, Vol. 34, 2003, pp. 183211. doi:10.1146/annurev.ecolsys.34.011802.132403

[2] J. M. Nagel and K. L. Griffin, "Can Gas-Exchange Characteristics Help Explain the Invasive Success of Lythrum salicaria?" Biological Invasions, Vol. 6, No. 1, 2004, pp. 101-111. doi:10.1023/B:BINV.0000010125.93370.32

[3] Y. L. Feng, G. L. Fu and Y. L. Zheng, "Specific Leaf 
Area Relates to the Differences in Leaf Construction Cost, Photosynthesis, Nitrogen Allocation, and Use Efficiencies between Invasive and Noninvasive Alien Congeners," Planta, Vol. 228, No. 3, 2008, pp. 383-390. doi:10.1007/s10530-008-9240-3

[4] Z. Baruch and G. Goldstein, "Leaf Construction Cost, Nutrient Concentration, and $\mathrm{Net} \mathrm{CO}_{2}$ Assimilation of $\mathrm{Na}-$ tive and Invasive Species in Hawaii," Oecologia, Vol. 121, No. 2, 1999, pp. 183-192. doi: $10.1007 / \mathrm{s} 004420050920$

[5] M. R. Leishman, T. Haslehurst, A. Ares and Z. Baruch, "Leaf Trait Relationships of Native and Invasive Plants: Community and Global Scale Comparisons," New Phytologists, Vol. 176, No. 3, 2007, pp. 635-643. doi:10.1111/j.1469-8137.2007.02189.x

[6] J. L. Funk and P. M. Vitousek, "Resource-Use Efficiency and Plant Invasion in Low-resource Systems," Nature, Vol. 446, No. 7139, 2007, pp. 1079-1081. doi:10.1038/nature05719

[7] J. M. Nagel and K. L. Griffin, "Construction Cost and Invasive Potential: Comparing Lythrum salicaria (Lythraceae) with Co-Occurring Native Species along Pond Banks," American Journal of Botany, Vol. 88, No. 12, 2001, pp. 2252-2258.

[8] O. O. Osunkoya, D. Bayliss, F. D. Panetta and G. V. Smith, "Leaf Trait Co-ordination in Relation to Construction Cost, Carbon Gain and Resource-Use Efficiency in Exotic Invasive and Native Woody Vine Species," Annals of Botany, Vol. 106, No. 2, 2010, pp. 371-380. doi:10.1093/aob/mcq119

[9] V. Matzek, "Superior Performance and Nutrient-Use Efficiency of Invasive Plants over Non-Invasive Congeners in a Resource-Limited Environment," Biological Invasions, Vol. 13, 2011, pp. 3005-3014. doi:10.1007/s10530-011-9985-y

[10] X. Y. Shen, S. L. Peng, B. M. Chen, J. X. Pang, L. Y. Chen, H. M. Xu and Y. P. Hou, "Do Higher Resource Capture Ability and Utilization Efficiency Facilitate the Successful Invasion of Native Plants?" Biological Invasions, Vol. 13, No. 4, 2011, pp. 869-881. doi:10.1007/s10530-010-9875-8

[11] L. F. Jiang, Y. Q. Luo, J. K. Chen and B. Li, "Ecophysiological Characteristics of Invasive Spartina alterniflora and Native Species in Salt Marshes of Yangtze River Estuary, Estuarine," Coastal and Shelf Science, Vol. 81, No. 1, 2009, pp. 74-82. doi:10.1016/j.ecss.2008.09.018

[12] J. N. Boyd, C. Y. Xu and K. L. Griffin, "Cost-Effectiveness of Leaf Energy and Resource Investment of Invasive Berberis thunbergii and Co-Occurring Native Shrubs," Canadian Journal of Forest Research, Vol. 39, No. 11, 2009, pp. 2109-2118. doi:10.1139/X09-128

[13] Y. L. Feng, Y. L. Feng, Y. P. Li, R. F. Wang, R. M. Callaway, A. V. Banuet and Inderjit, "A Quicker Return Energy-Use Strategy by Populations of a Subtropical Invader in the Non-Native Range: A Potential Mechanism for the Evolution of Increased Competitive Ability," Journal of Ecology, Vol. 99, No. 5, 2011, pp. 1116-1123. doi:10.1111/j.1365-2745.2011.01843.x
[14] A. J. Sosa, M. H. Julien and H. A. Cordo, "New Research on Alternanthera philoxeroides (Alligator Weed) in Its South American Native Range," In: J. M. Cullen, D. T. Briese, D. J. Kriticos, W. M. Lonsdale, L. Morin, J. K. Scott, Eds., Proceedings of the XI International Symposium on Biological Control of Weeds, CSIRO Entomology, Canberra, 2004, pp. 180-185.

[15] X. Y. Pan, Y. P. Geng, A. J. Sosa, W. J. Zhang, B. Li and J. K. Chen, "Invasive Alternanthera philoxeroides, Biology, Ecology \& Management," Acta Phytotaxonomica Sinica, Vol. 45, No. 6, 2007, pp. 884-900 (in Chinese).

[16] X. Y. Pan, Y. P. Geng, W. J. Zhang, B. Li and J. K. Chen, "The Influence of Abiotic Stress and Phenotypic Plasticity on the Distribution of Invasive Alternanthera philoxeroides along a Riparian Zone," Acta Oecologica, Vol. 30, No. 3, 2006, pp. 333-341. doi:10.1016/j.actao.2006.03.003

[17] Y. P. Geng, X. Y. Pan, C. Y. Xu, W. J. Zhang, B. Li and J. K. Chen, "Phenotypic Plasticity of Invasive Alternanthera philoxeroides in Relation to Different Water Availability, Comparing to Its Native Congener," Acta Oecologica, Vol. 30, No. 3, 2006, pp. 380-385. doi:10.1016/j.actao.2006.07.002

[18] X. Jia, X. Y. Pan, B. Li, J. K. Chen and X. Z. Yang, “Allometric Growth, Disturbance Regime, and Dilemmas of Controlling Invasive Plants: A Model Analysis," Biological Invasions, Vol. 11, No. 3, 2009, pp. 743-752. doi:10.1007/s10530-008-9288-0

[19] X. Jia, X. Y. Pan, A. J. Sosa, B. Li and J. K. Chen, "Differentiation in Growth and Biomass Allocation among Three Native Alternanthera philoxeroides Varieties from Argentna," Plant Species Biology, Vol. 25, No. 2, 2010, pp. 85-92. doi:10.1111/j.1442-1984.2010.00271.X

[20] X. Y. Pan, X. Jia, J. Zeng, A. J. Sosa, B. Li and J. K. Chen, "Stem Tissue Mass Density Is Linked to Growth and Resistance to a Stem-Boring Insect in Alternanthera philoxeroides," Plant Species Biology, Vol. 26, No. 1, 2011, pp. 58-66. doi:10.1111/j.1442-1984.2010.00307.x

[21] S. H. Kay and W. T. Haller, "Evidence for the Existence of Distinct Alligator Weed Biotypes," Journal of Aquatic Plant Management, Vol. 20, No. 1, 1982, pp. 37-41.

[22] H. Poorter and R. Villar, "The Fate of Acquired Carbon in Plants: Chemical Composition and Construction Costs," In: F. A. Bazzaz and J. Grace, Eds., Plant Resource Allocation, Academic Press, San Diego, 1997, pp. 39-72.

[23] N. Vertregt and F. W. T. Penning de Vries, "A Rapid Method for Determining the Efficiency of Biosynthesis of Plant Biomass," Journal of Theoretical Biology, Vol. 128, No. 1, 1987, pp. 109-119. doi:10.1016/S0022-5193(87)80034-6

[24] H. Poorter, "Construction Costs and Payback Time of Biomass: A Whole Plant Perspective," In: J. Roy and E. Gamier, Eds., A Whole Plant Perspective on Carbon-Nitrogen Interactions, SPB Academic Publishing, Hague, 1994, pp. 111-127.

[25] M. L. Navas, B. Ducout, C. Roumet, J. Richarte, J. Garnier and E. Garnier, "Leaf Life Span, Dynamics and Construction Cost of Species from Mediterranean Old-Fields 
Differing in Successional Status," New Phytologists, Vol. 159, No. 1, 2003, pp. 213-228. doi:10.1046/j.1469-8137.2003.00790.x

[26] G. D. Farquhar, S. von Caemmer and J. A. Berry, “A Biochemical-Model of Photosynthetic $\mathrm{CO}_{2}$ Assimilation in Leaves of $\mathrm{C}_{3}$ Species," Planta, Vol. 149, No. 1, 1980, pp. 78-90. doi:10.1007/BF0038623

[27] C. Field and H. A. Mooney, "The Photosynthesis-Nitrogen Relationships in Wild Plants," In: T. J. Givnish, Ed., On the Economy of Plant Form, Function, Cambridge University Press, Cambridge, 1986, pp. 25-55.

[28] J. M. Nagel, X. Z. Wang, J. D. Lewis, H. A. Fung, D. T. Tissue and K. L. Griffin, "Atmospheric $\mathrm{CO}_{2}$ Enrichment Alters Energy Assimilation, Investment and Allocation in Xathum strumarium," New Phytologists, Vol. 166, No. 2, 2005, pp. 513-523. doi:10.1111/j.1469-8137.2005.01341.x

[29] Y. Onoda, K. Hikosaka and T. Hirose, "Allocation of Nitrogen to Cell Walls Decreases Photosynthetic NitrogenUse Efficiency," Functional Ecology, Vol. 18, No. 3, 2004, pp. 419-425. doi:10.1111/j.0269-8463.2004.00847.x.

[30] Y. L. Feng, Y. B. Lei, R. F. Wang, R. M. Callaway, A. V. Banuet, Inderjit, Y. P. Li and Y. L. Zheng, "Evolutionary Tradeoffs for Nitrogen Allocation to Photosynthesis versus Cell Walls in an Invasive Plant," PNAS, Vol. 106, No. 6, 2009, pp. 1853-1856. doi:10.1073/pnas.0808434106

[31] K. Hikosaka, "Interspecific Difference in the Photosynthesis-Nitrogen Relationship: Patterns, Physiological Causes, and Ecological Importance," Journal of Plant Research, Vol. 117, No. 6, 2004, pp. 481-494. doi:10.1007/s10265-004-0174-2 